\title{
Development of a Process Envelope for Friction Stir Welding of DH36 Steel - A Step Change
}

\author{
Athanasios Toumpis ${ }^{a *}$, Alexander Galloway ${ }^{a}$, Stephen Cater ${ }^{b}$, Norman \\ McPherson ${ }^{\mathrm{C}}$ \\ ${ }^{a}$ Department of Mechanical \& Aerospace Engineering, University of Strathclyde, James Weir \\ Building, 75 Montrose Street, Glasgow G1 1XJ, United Kingdom \\ ${ }^{b}$ Friction and Forge Processes Department, Joining Technologies Group, TWI Technology \\ Centre (Yorkshire), Advanced Manufacturing Park, Wallis Way, Catcliffe, Rotherham S60 5TZ, \\ United Kingdom \\ ${ }^{c}$ BAE Systems Naval Ships, 1048 Govan Road, Glasgow G51 4XP, United Kingdom
}

\begin{abstract}
Friction stir welding of steel presents an array of advantages across many industrial sectors compared to conventional fusion welding techniques. However, the fundamental knowledge of the friction stir welding process in relation to steel remains relatively limited. A microstructure and property evaluation of friction stir welded low alloy steel grade DH36 plate, commonly used in ship and marine applications has been undertaken. In this comprehensive study, plates of $2000 \times 200 \times 6 \mathrm{~mm}$ were butt welded together at varying rotational and traverse speeds. Samples were examined microscopically and by transverse tensile tests. In addition, the work was complemented by Charpy impact testing and micro-hardness testing in various regions of the weld. The study examined a wide range of process parameters; from this, a preliminary process parameter envelope has been developed and initial process parameter sets established that produce commercially attractive excellent quality welds through a substantial increase in the conventionally recognised weld traverse speed.
\end{abstract}

Keywords: Friction stir welding; Optimisation; DH36.

* Corresponding author. Tel.: +44 (0)7513 621 906, e-mail address: athanasios.toumpis@strath.ac.uk 


\section{Introduction}

Friction stir welding (FSW), invented by Wayne Thomas [1] at TWI in December 1991, is a solid state joining process in which a constantly rotating, cylindricalshouldered tool with a profiled probe is traversed at a constant rate along the joint between two clamped pieces of butted material. The probe is slightly shorter than the weld depth required, with the tool shoulder riding along the top of the work piece surface. The material is thermo-mechanically worked and heated high enough for plastic deformation to occur but well below its melting point. The basic concept of the process is shown in Figure 1.

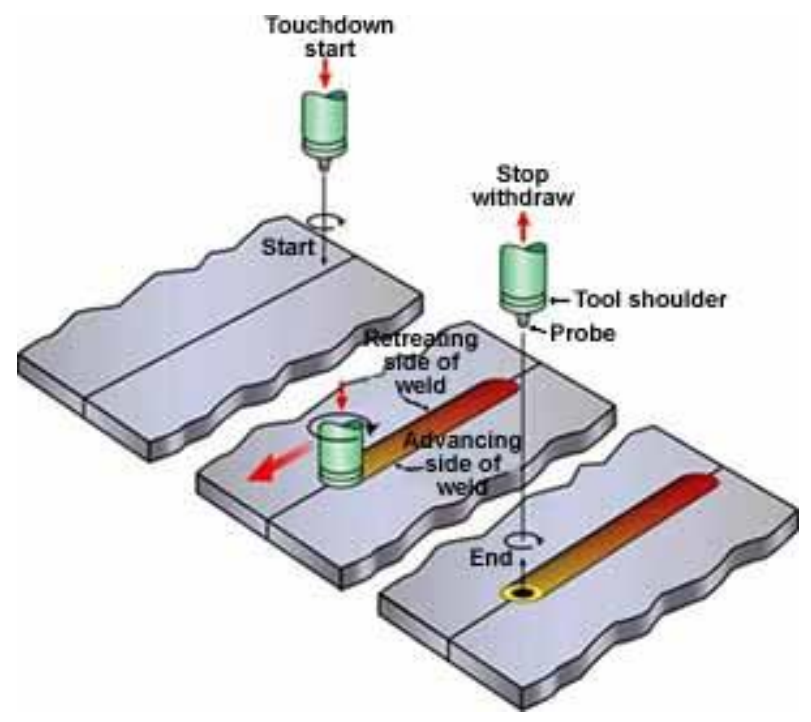

Fig. 1. The basic concept of friction stir welding.

Frictional heat is generated between the tool and the work pieces. This heat, along with that produced by the mechanical mixing process and the adiabatic shearing within the material causes the stirred materials to soften without melting. As the tool is moved forward, a special profile on the probe forces plasticised material to the rear where clamping force assists in a forged consolidation of the weld. This process of the tool traversing along the weld line in a plasticised tubular shaft of metal results in severe solid state deformation involving dynamic recrystallization of the base material. FSW is a very complex multi-physics process incorporating mechanical and thermal processing of the material, considerable plastic deformation and high levels of flow stress; it is a process analogous to forging rather than casting which more closely resembles the conditions observed during conventional fusion welding.

FSW is currently being extensively employed in aluminium joining applications but there is significant interest by many industrial sectors in transferring the process and its advantages to steel. Preliminary studies have demonstrated the feasibility of FSW of steel [2,3], while others have shown that there are several positive effects on the properties of friction stir welded steel plates such as 
considerable grain refinement, excellent fatigue properties and minimised distortion [4].

The current study is focusing on FSW of steel grade DH36, a low alloy steel utilised in the European shipbuilding industry among other sectors. For FSW of steel to become economically and technically viable for introduction in the shipbuilding industry, it should evolve into a process competitive with conventional fusion welding methods. In the shipbuilding sector, this requirement is translated into high welding speeds (in millimetres per minute) which produce welded joints of acceptable quality. Therefore, an optimisation study is a fundamental step towards this direction; that is, a study concerned with establishing the limits of the process (the process envelope) in terms of the two more significant parameters which can be directly controlled, tool traverse speed and tool rotational speed.

There are limited studies thus far for FSW of structural steel in the relevant technical literature, particularly for high welding speeds. In a well cited study from 2003, Reynolds et al. [3] examine friction stir single sided welds of hot rolled, $6.4 \mathrm{~mm}$ thick DH36 steel, produced by four different welding speeds in an inert gas environment, to assess the relationship between varying weld parameters and resultant weld properties. They [3] observe a bainitic and martensitic microstructure in the bulk of the thermo-mechanically affected zone (weld nugget) of the fast weld $(450 \mathrm{~mm} / \mathrm{min})$. However, only this weld's microstructural features are reported therefore no comparison can be made to the intermediate and slower welds. The hardness of all welds demonstrates a continuous increase from parent material to nugget, with a variation of approximately $190 \mathrm{HV}$ up to the peak hardness of the fast weld. The tensile tests reveal significant overmatching of all welds; longitudinal tensile tests show that the yield strength of all welds is higher than the parent material's UTS, and this is attributed to the weld nugget microstructure being very different from the original ferrite / pearlite microstructure. In all, weld hardness and strength is seen to increase with increasing welding speed. The effect of increasing rotational speed on weld properties is not considered in this study [3].

Further work [4] on the same grade of steel, DH36, extends the mechanical properties assessment of friction stir welded plates, also examining three different thicknesses $(4,6$, and $8 \mathrm{~mm})$ and comparing to submerged arc welded (SAW) plates of same thickness, in order to evaluate the potential of FSW as a shipbuilding welding process. McPherson et al. [4] observe an acicular shaped ferrite microstructure in the thermo-mechanically affected zone, consistent over the mid-thickness of all weld samples, and a finer unspecified structure seemingly increasing with decreasing plate thickness. The parent material is seen to consist of bands of ferrite and pearlite, as expected for rolled steel plates. Variations in hardness distribution are considered minor and certainly not expected to produce adverse effects. Likewise, impact toughness levels for FSW and SAW samples at $-20^{\circ} \mathrm{C}$ are reported to be similar and within classification society impact requirements. The focus of this study [4] is shifted 
towards the previously mentioned mechanical properties therefore the welds' tensile behaviour is not discussed in detail; all transverse tensile samples however fractured in the parent material. In conclusion, this study [4] supports sufficiently the argument for the capability of FSW to match shipbuilding requirements.

Ghosh et al. [5] study the friction stir lap welding of thin plates of high strength martensitic M190 steel by optical microscopy, tensile lap shear testing and micro-hardness testing. Their objective is to optimise the FSW of M190 steel in the automotive industry by assessing the resultant microstructure and mechanical properties produced by ten different sets of welding parameters, 600-1200 rpm rotational speed and 51-203 $\mathrm{mm} / \mathrm{min}$ traverse speed, also applying forced air cooling. The researchers [5] find that with increasing traverse and rotational speed, the microstructure of the weld nugget becomes predominantly martensitic due to very high cooling rate. Bainite is seen to appear and gradually increase with the same rotational speed but slower traverse speeds, hence marginally lower cooling rates. They conclude that the temperature of the inner heat affected zone reached above the steel's $A_{1}$ temperature during welding thus austenite transformed into ferrite and pearlite during cooling. Still, the outer heat affected zone temperature remains below $A_{1}$ therefore exhibiting tempered martensite because of the martensitic parent material and the amount of heat dissipating through this region. The results of the tensile shear tests show that all samples fractured in the vicinity of the inner heat affected zone that seems to be the weakest region due to its ferritepearlite microstructure. Ghosh et al. [5] however do not proceed in developing new sets of parameters which will improve the mechanical properties of the weld zone, consequently weakening their case for an optimisation study.

In an investigation into the possible use of FSW as an alternative to electric resistance welding of API X100 grade high strength linepipe steel, Cho et al. [6] examine its microstructural evolution during friction stir butt welding after significant prior preparation of the plates. Their work is mainly focused on the grain structure development in a single set of process parameters, $127 \mathrm{~mm} / \mathrm{min}$ and $450 \mathrm{rpm}$, using optical microscopy, EBSD-SEM and TEM. Starting from the parent material microstructure of dual phase ferrite and bainite, the thermomechanically affected zone is reported as having a very fine, homogeneous microstructure while the stir zone is acicular shaped bainitic ferrite rich. The former is attributed to continuous dynamic recrystallization, while the latter occurs because of the particular to this region austenite to ferrite phase transformation under high cooling rate and high strain. Possible heterogeneity of the weld is not discussed however as the microstructural assessment is concentrating only on the retreating side of the weld zone. The micro-hardness measurements [6] show that stir zone hardness is significantly higher than all other regions, mainly due to its developed microstructure. No other mechanical properties of the weld are presented. 
There are many relevant optimisation studies for FSW of aluminium alloys including modelling, statistical analysis or experimental work, but they seem rather small scale projects when compared to the present work, and therefore cannot be transferred into FSW of steel. For example, Kumar et al. [7] attempt to optimise the FSW of two dissimilar aluminium alloys with regard to tensile properties and hardness of the weld, with no commentary on the microstructural evolution of the thermo-mechanically affected zone. They [7] also explore the effect of each parameter (rotational speed, tool tilt and type of tool pin) on these properties by percentage contribution, as derived from their statistical analysis. Kumar et al. [7] employ the Taguchi method to direct their analysis but this approach leads them to experimentally examine only nine sets of parameters; in fact, traverse speed, although highly significant, is not one of these parameters. Hence their conclusions are vague and limited.

Ghosh et al. [8] investigate the FSW process on two dissimilar aluminium alloys for optimised strength and formability by developing appropriate sets of parameters (rotational speed and traverse speed). They conclude [8] that components welded at the lowest rotational and traverse speed possess improved mechanical properties, more refined grains and decreased residual stresses. In their study, the researchers [8] use the findings of previous studies $[9,10]$ for FSW of each of the two alloys individually. They then proceed in selecting only four sets of parameters to optimise the welding of both alloys but without further discussing how these parameters were chosen. In addition, the effect of changing the position of the two alloys, from left to right before welding, on the resultant microstructure and mechanical properties is not reported.

In the present study and in contrast to previous process parameter development studies in aluminium alloys, 19 friction stir welds, the majority of which were produced with welding speeds not previously identified by other research groups, were extensively examined in order to determine a step change improvement to the current industrially accepted welding speeds. These were selected from a comprehensive and considerable spread of FSW DH36 butt joints in which slow, intermediate and fast welding speeds were trialled. This extensive work, the first of its kind on steel, has led to an initial understanding towards developing the fundamental knowledge on friction stir welding of steel.

\section{Development of process parameter envelope}

The process parameter envelope for FSW of DH36 steel can be represented by plotting the two more important weld parameters, tool rotational speed and traverse speed as variables on the $x$ and $y$ axes of a graph (Figure 2). The development of the envelope begins with a set of parameters that are known to deliver acceptable quality welds on steel. It is then broadened outwards from these parameters, with varying rotational and traverse speeds, in order to 
establish the outer limits of the process envelope by producing and examining a series of welds. The envelope consists of the parameter sets that produce welds of at least acceptable quality, and is divided in this case into three groups characterised by welding (traverse) speed. The shape of this envelope is expected to vary with any further development and refinement of the process parameters. To generate the process envelope, extensive welding and considerable testing is required over a very large data set.

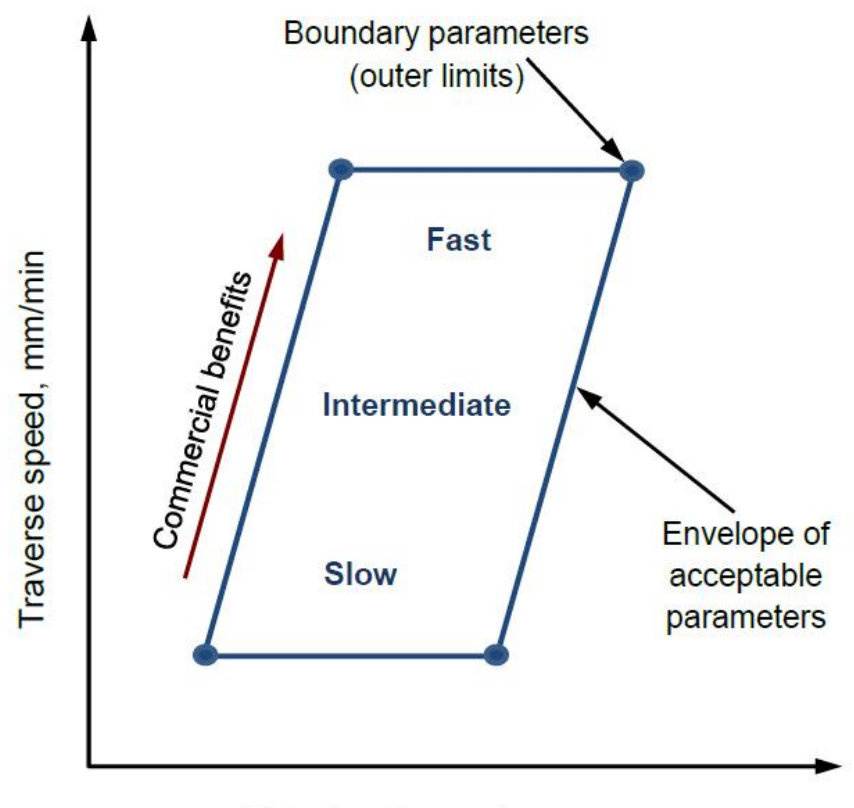

Rotational speed, rpm

Fig. 2. Schematic representation of the process parameter envelope.

The process parameter envelope development in the present study commenced using the process parameters recommended by the FSW tool manufacturer, MegaStir Inc. of Provo, Utah, USA. These are based upon a tool traverse speed of $100 \mathrm{~mm} / \mathrm{min}$ and a tool rotational speed of $200 \mathrm{rpm}$. In simplistic terms, the tool rotational speed controls the frictional heat input to the weld zone and plasticises the steel whilst the tool traverse speed influences the weld cooling rate and thus has a significant effect upon the evolving microstructure. Other factors, for example the tool tilt, tool plunge depth, tool cooling, backing bar characteristics and clamping arrangements have a secondary but not insignificant effect upon the welding process.

The process parameters used cannot be considered in isolation from the tool itself. Whilst it is desirable to use process parameters that produce the best weld in terms of microstructure and mechanical properties, the current tool technology for FSW of steel is still relatively immature and attention must be paid to ensure that the welding environment is not so aggressive that the tool's life is shortened by the welding process. A compromise must therefore be made between selecting parameters that deliver good weld properties and parameters that extend the life of the tool and thereby improve the economic viability of the FSW process in steel. 
In the present study, a number of welds were initially produced using the previously stated process parameters as this provided a baseline data set of the generated forces, torques and heat inputs resulting from these parameters. These data framed the basis for expanding the process envelope to higher welding speeds.

It is desirable that FSW is competitive to conventional fusion welding techniques in terms of welding speed, hence the process parameters were extended to explore the potential to use higher welding traverse speeds. Thus, if the tool is to be traversed through the steel being welded more quickly, then it is necessary to establish that the steel ahead of the tool is sufficiently plasticised to ensure that the forces experienced by the tool do not increase to the point where the tool fails, and the steel continues to flow around the tool and can be consolidated behind it effectively.

To weld at higher traverse speeds, the tool rotational speed needs to be increased. Increasing the tool rotational speed increases the heat input to the weld, but does not do so in a linear manner; above a certain point, the friction couple between the steel and the tool changes and the heat input into the weld can decrease. Parameter selection is therefore a complex process with many interdependent variables, many of which are currently poorly understood.

Once a baseline understanding of the welding process was achieved, the primary process parameters of tool rotational speed and tool traverse speed were increased. The objective was to increase the welding speed from 100 $\mathrm{mm} / \mathrm{min}$ to $350 \mathrm{~mm} / \mathrm{min}$, the point at which FSW would become competitive to fusion welding processes in terms of production speed of acceptable quality. Further increases in welding speed beyond $350 \mathrm{~mm} / \mathrm{min}$ are desirable to improve the competitiveness of FSW, thus faster welding speeds were also investigated. Table 1 shows the welding speeds investigated in this initial process parameter development work. The heat input calculations are based on the equation presented by McPherson et al. [4] such that: $\mathrm{H}=\varepsilon 2 \pi R T / 1000 \mathrm{~V}$, where $\varepsilon$ dimensionless factor of FSW process efficiency, $R$ rotational speed in rpm, $T$ average steady state torque on the tool in $\mathrm{Nm}$, and $V$ traverse speed in $\mathrm{mm} / \mathrm{min}$.

Table 1

List of weld parameters examined.

\begin{tabular}{ccccc}
\hline $\begin{array}{c}\text { Reference } \\
\text { number }\end{array}$ & $\begin{array}{c}\text { Rotational Speed } \\
(\mathbf{r p m})\end{array}$ & $\begin{array}{c}\text { Traverse Speed } \\
(\mathbf{m m} / \mathbf{m i n})\end{array}$ & $\begin{array}{c}\text { Heat Input } \\
(\mathbf{k J} / \mathbf{m m})\end{array}$ \\
\hline W019A & 200 & 100 & 3.44 \\
W019B & 200 & 110 & 3.07 & \\
W019C & 200 & 120 & 2.68 & ठ \\
W020A & 200 & 130 & 2.61 & ๘ \\
W020B & 200 & 143 & 2.31 & \\
W020C & 200 & 156 & 2.04 \\
\hline
\end{tabular}




\begin{tabular}{|c|c|c|c|c|}
\hline W021 & 400 & 200 & 3.07 & \multirow{8}{*}{ 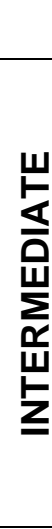 } \\
\hline W022 & 400 & 250 & 2.29 & \\
\hline W023 & 400 & 275 & 2.13 & \\
\hline W027 & 400 & 325 & 1.77 & \\
\hline W028 & 400 & 375 & 1.45 & \\
\hline W029 & 450 & 400 & 1.61 & \\
\hline W030 & 450 & 350 & 1.97 & \\
\hline W031 & 300 & 250 & 1.92 & \\
\hline W032 & 600 & 500 & 1.77 & \multirow{5}{*}{ 占 } \\
\hline W033 & 650 & 500 & 2.12 & \\
\hline W034 & 575 & 500 & 1.35 & \\
\hline W035 & 700 & 500 & 2.23 & \\
\hline W036 & 675 & 500 & 2.01 & \\
\hline
\end{tabular}

Through this process parameter development, the state of the art has been increased from conventionally adopted welding speed of $100 \mathrm{~mm} / \mathrm{min}$ to a more commercially attractive speed of $400 \mathrm{~mm} / \mathrm{min}$. Although a step change in the welding speed has been identified, the purpose of the present study is to assess the impact of this increase on the microstructural evolution and mechanical properties of each friction stir weld.

\section{Experimental procedures}

\subsection{Material and welding details}

A substantial number of single sided friction stir butt welds in $6 \mathrm{~mm}$ thick DH36 steel were produced using a PowerStir FSW machine operated in position control. All plates were $2000 \mathrm{~mm}$ in length and $200 \mathrm{~mm}$ in width, therefore fabricating a welded component of $400 \mathrm{~mm}$ in width. The rolled plates were welded in the as received condition and were heavily clamped to the machine bed, without any prior surface preparation. The nominal chemical composition of the shipbuilding steel grade $\mathrm{DH} 36$ which was examined in this study is presented in Table 2, as provided by the steel supplier.

Table 2

Chemical composition of $6 \mathrm{~mm}$ thick DH36 steel (wt\%).

\begin{tabular}{cccccccc}
\hline $\mathbf{C}$ & $\mathbf{S i}$ & $\mathbf{M n}$ & $\mathbf{P}$ & $\mathbf{S}$ & $\mathbf{A l}$ & $\mathbf{N b}$ & $\mathbf{N}$ \\
\hline 0.11 & 0.37 & 1.48 & 0.014 & 0.004 & 0.02 & 0.02 & 0.002 \\
\hline
\end{tabular}


Friction stir welding was performed using the current leading FSW tool technology for steel, this being the WRe-pcBN Q70 stepped spiral tool to design M44837 (Figure 3). This tool is equipped with a scrolled shoulder, having a probe length of $5.7 \mathrm{~mm}$ and rotating anti-clockwise. The tool is protected by an inert gas environment against oxidation due to the high temperatures of the FSW process.

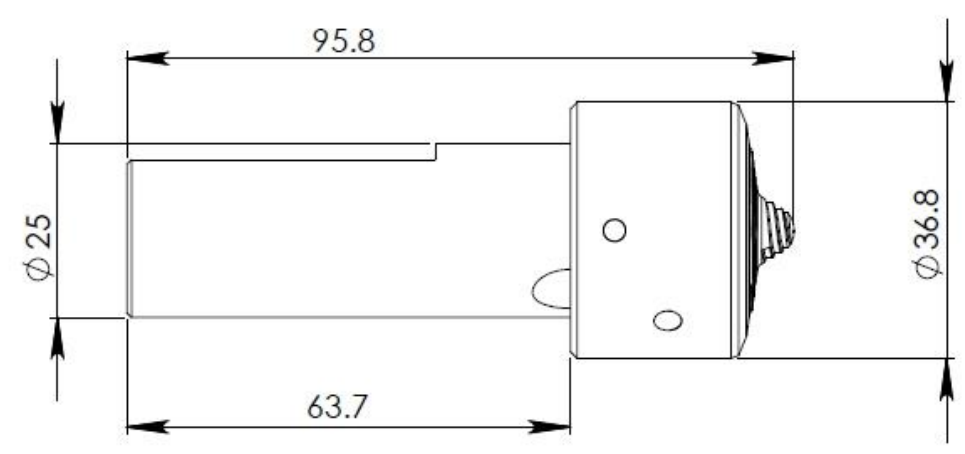

Fig. 3. Basic dimensions of the FSW tool employed for this study.

\subsection{Microstructure evaluation}

Microstructural characterisation was undertaken towards establishing the limits of the FSW process. One outcome of this microstructural assessment is generating important information regarding the mechanical properties that are likely to be attained in the weld zone. A secondary outcome is providing information related to undesirable process induced defects or flaws that could compromise the integrity of the weld, the absence of which provides reassurance that the weld process parameters reported in Table 1 will lead to an acceptable level of quality. The resultant microstructure and its possible variations throughout the weld region are thoroughly examined and reported herein.

One metallography sample was transversely sectioned from a random position within the steady state condition region of each of the nineteen welds. In the steady state region, the forces that the FSW tool sustains stabilise (Figure 4), the weld quality is improved, and any sample removed from any position within the steady state region is expected to be representative of the properties of the entire weld. The region of steady state condition is commonly identified by visual observation of the welded plates (a good quality surface without excessive flash formation, voids or cracks), and confirmed by analysis of the forces (on the longitudinal and vertical direction) on the tool; this is typically established beyond the first $150 \mathrm{~mm}$ of welding. 


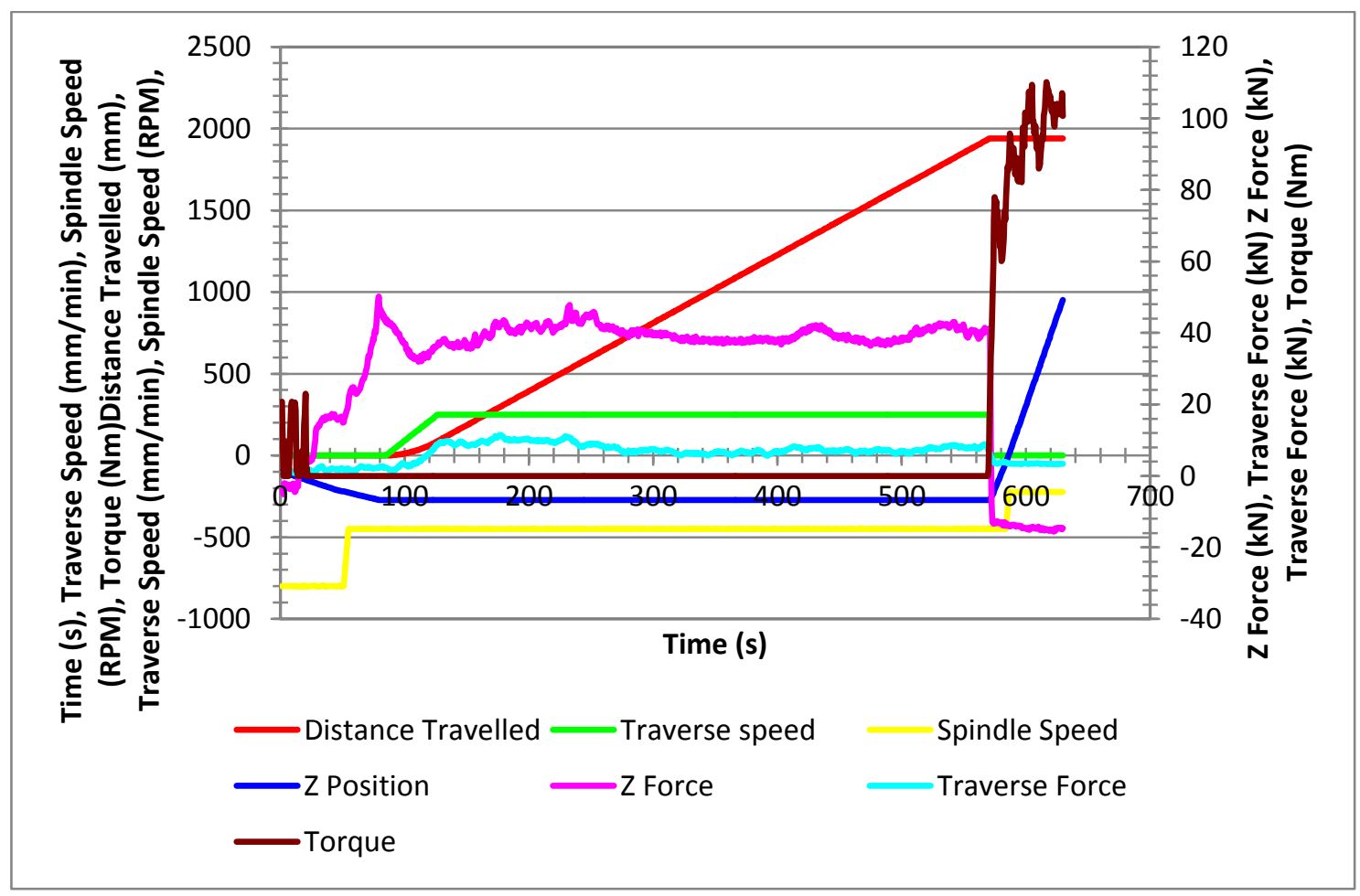

Fig. 4. Typical chart of tool position, force and torque data measured by the welding machine during FSW.

A consistent metallographic preparation process was applied on each sample examined and this process made use of the normal met-prep equipment and consumables. The process consisted of hot mounting, grinding and polishing on a semi-automatic preparation machine, followed by etching with Nital $2 \%$. The samples were then positioned on a stage and macro-graphic images of the weld zone were captured. A more detailed examination of areas of interest within the weld region identified on the macro-graphs was performed with the aid of a light optical microscope that involved taking several micrographic images from each sample being studied.

\subsection{Tensile testing}

Transverse tensile tests were conducted in parallel to the microstructural examination study to further support the development of the process envelope, in that the transverse tensile strength was assessed using a consistent testing program. This testing program enabled the determination of the yield strength (YS) and ultimate tensile strength (UTS) that the applied sets of weld parameters produce on the welded plates, along with the position of the fracture (parent material or weld metal).

All transverse tensile tests were performed on an Instron 8802 servo-hydraulic uniaxial tensile testing system in accordance with ISO Standards [11]. Three samples were sectioned from each weld presented in Table 1 as per the same specifications in order to improve the repeatability of results (Figure 5). In addition, three samples were sectioned and tested from the parent material 
(PM) of three randomly selected welded plates but in parallel to the weld direction. Thus, the mechanical properties of DH36 in the longitudinal direction were established and provided values for comparison. The consistent control method used was an extension rate of $0.5 \mathrm{~mm} / \mathrm{min}$ up to extension of $1.25 \mathrm{~mm}$, then $5 \mathrm{~mm} / \mathrm{min}$ up to fracture.

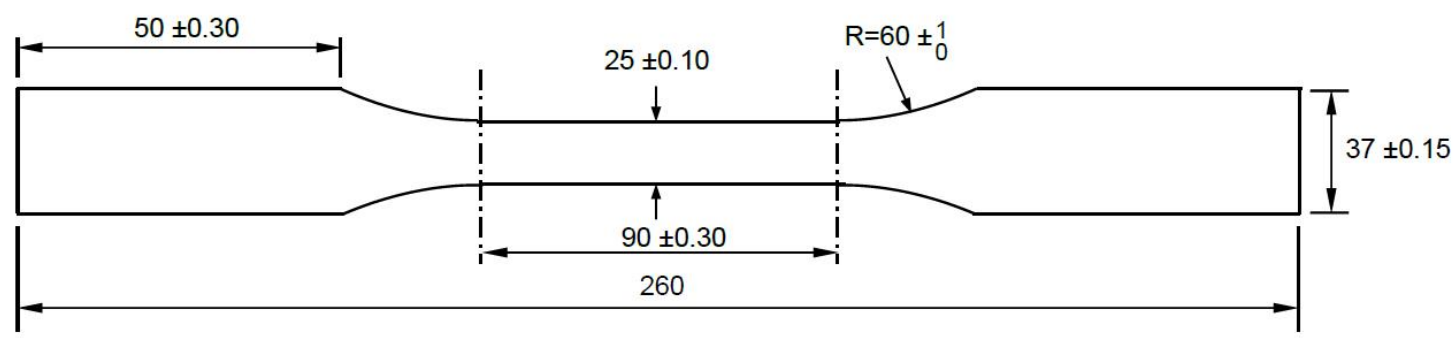

Fig. 5. Transverse tensile test sample of rectangular cross section (thickness $6 \mathrm{~mm}$ ).

\subsection{Hardness and impact toughness}

Micro-hardness measurements were taken across the entire weld zone using a Mitutoyo hardness tester. The measurements were performed by applying a load of $200 \mathrm{gf}$ and using a grid spacing of $1 \mathrm{~mm}$ (for both $\mathrm{x}$ and $\mathrm{y}$ directions) (Figure 6).

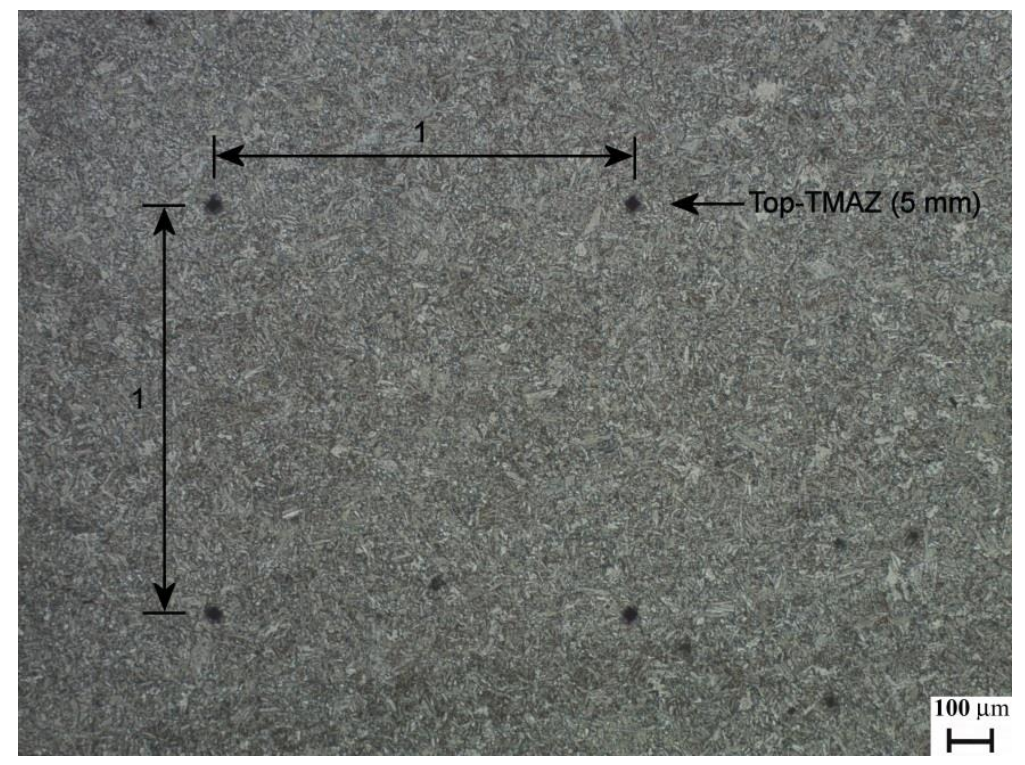

Fig. 6. Grid spacing for micro-hardness measurements, Image from weld W021 [x50, Etched].

Charpy impact tests with the standard V-notch were performed according to ISO Standards [12] in order to evaluate the toughness of the weld region in relation to the weld parameters used. Samples were sectioned perpendicular to the weld centreline and transverse to the weld direction (Figure 7). One sample was sectioned with the notch axis of symmetry on the weld centreline. To examine the full width of the weld region however, three additional samples were sectioned towards both sides of the weld in $1.5 \mathrm{~mm}$ increments (Figure 8). In this configuration, each sample with the notch axis at $4.5 \mathrm{~mm}$ from the weld 
centreline included a small percentage of parent material which was essentially the same for either side. All other samples fully consisted of thermomechanically stirred material.

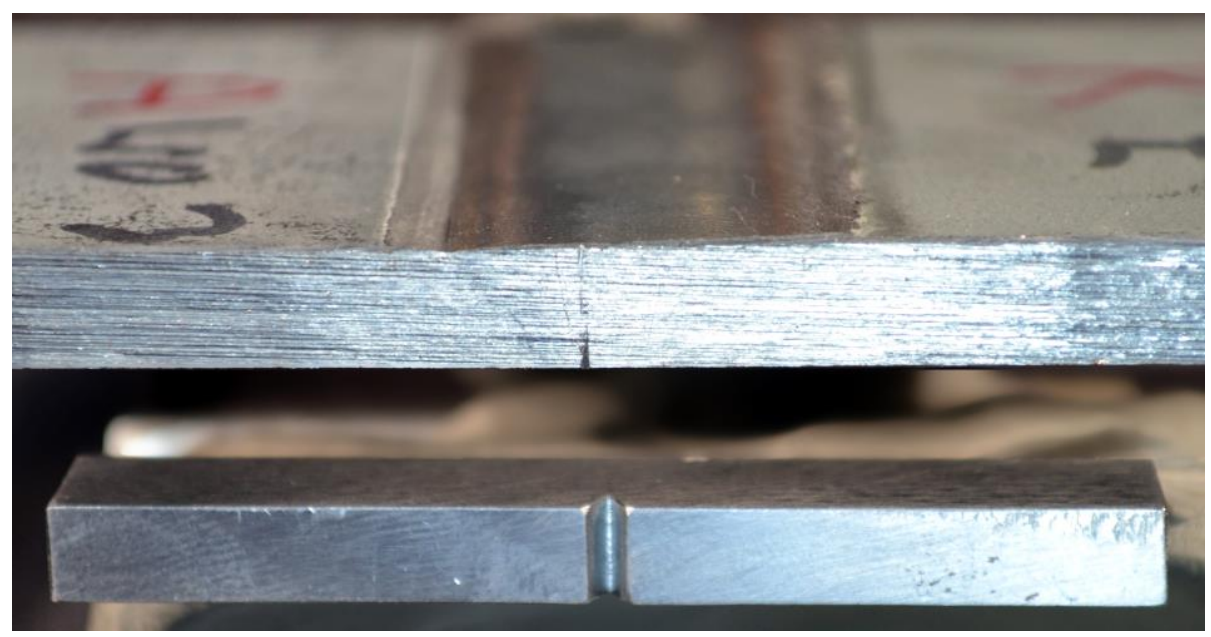

Fig. 7. Charpy sample and notch orientation (bottom) relative to welded plate section (top).

Reduced-section samples of $5 \mathrm{~mm}$ width were used due to the plate thickness of $6 \mathrm{~mm}$. In total, three sets of seven tests were performed in room temperature $\left(\sim 20^{\circ} \mathrm{C}\right)$ for each set of parameters to improve the accuracy of the results.

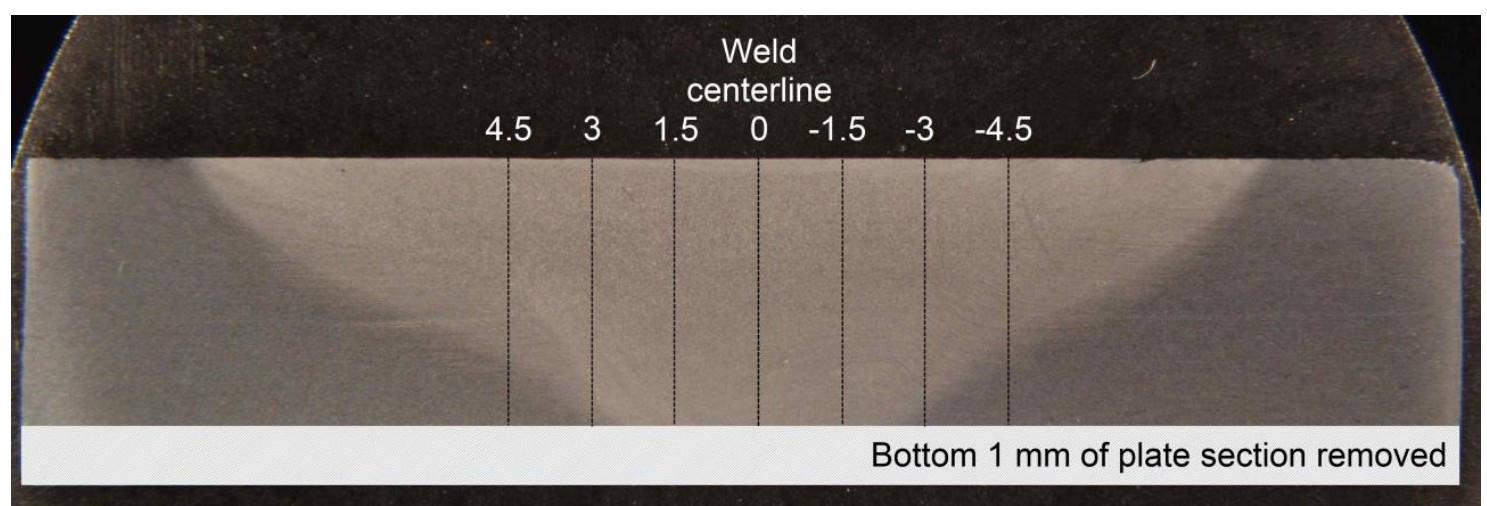

Fig. 8. Typical macro-graph showing the position of the notch axis of symmetry of the seven Charpy samples examined from each weld.

\section{Results and discussion}

\subsection{Microstructural observations}

The following nomenclature is adopted in the present study and the main regions of the weld zone are illustrated in Figure 9, where:

- AD: Advancing side, the side where the rotating FSW tool pushes the metal towards the weld direction, i.e. forwards. The convention employed for the 
entire project is that samples are prepared so that the advancing side is presented on the left side of all images.

- RT: Retreating side, the side where the rotating tool pushes the metal in a direction opposite to the weld direction, i.e. backwards.

- TMAZ: Thermo-mechanically affected zone in which the material has been thermo-mechanically stirred by the FSW tool.

- Weld root: part of TMAZ, around and below the tip of the FSW tool's pin.

- HAZ: Heat affected zone, where the metal has been affected by heat as it dissipates from the TMAZ, but not mechanically stirred.

- PM: Parent material, metal not affected by the process.

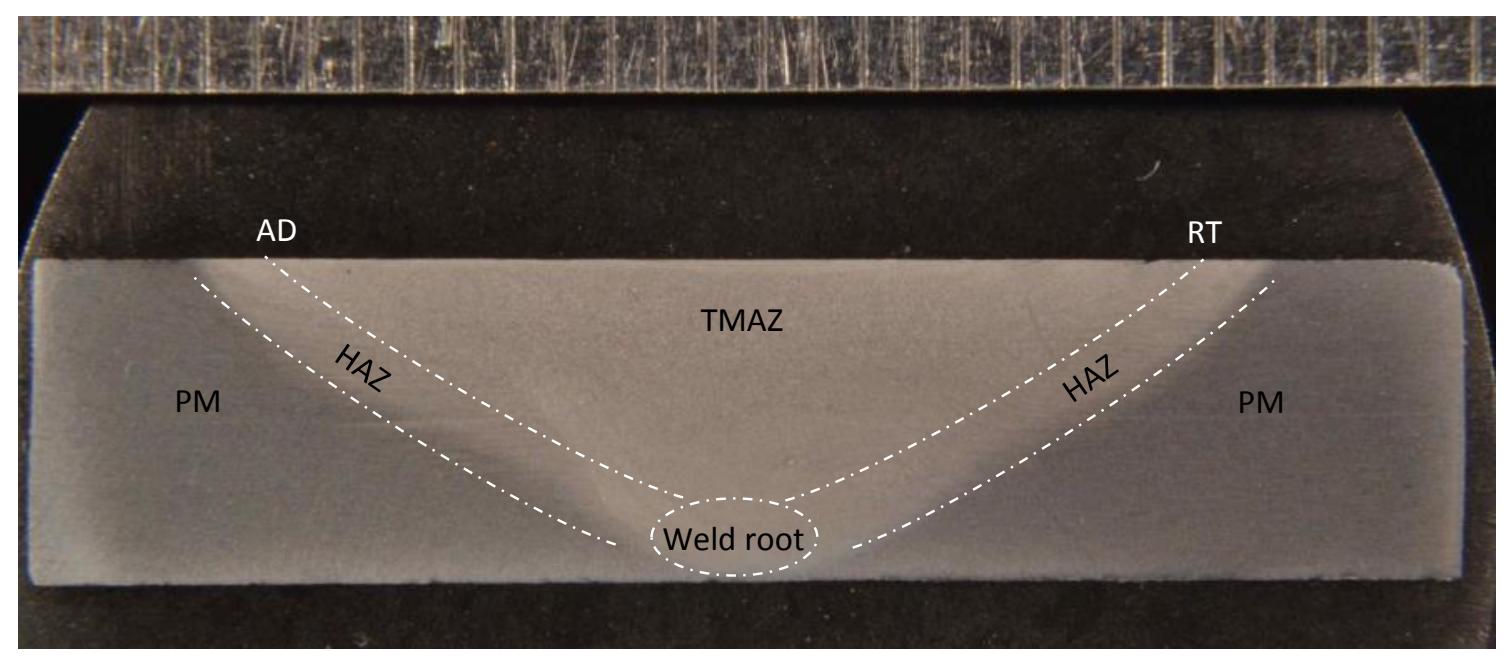

Fig. 9. A typical macrograph of the friction stir weld region.

Referring to the classification in Table 1, the group of slow welds presented a very homogeneous microstructure without any flaws. These exhibited a ferrite rich microstructure with highly refined grains of random geometry. A very small content of what is expected to be acicular-shaped bainitic ferrite was found in W019C (Figure 10), the content of which was seen to steadily increase with increasing traverse speed and constant rotational speed $(200 \mathrm{rpm})$. This observation confirms that the cooling rate is increasing with increasing traverse speed. Additionally, there appears to be a threshold value of approximately 130 $\mathrm{mm} / \mathrm{min}$ above which this apparently acicular bainitic ferrite microstructure occurs at a small ratio relative to the above described ferrite rich microstructure. The parameters of W019A, W019B and W019C resulted in welds being produced with a large and symmetrical tool footprint on the weld surface. Using a similar traverse speed of $127 \mathrm{~mm} / \mathrm{min}$, Cho et al. [6] observe a predominantly acicular shaped bainitic ferrite stir zone (TMAZ) microstructure developed as acicular bainitic ferrites nucleate mainly on the austenite grain boundaries. It is noted that this is a product of the phase transformation of austenite, in the supercritical stir zone (central TMAZ), to ferrite at a high cooling rate. Yet, comparing to the rotational speed of $200 \mathrm{rpm}$ which is used in the $100-156$ $\mathrm{mm} / \mathrm{min}$ range of traverse speeds of this study, the rotational speed of $450 \mathrm{rpm}$ employed by Cho et al. [6] seems high. That is, their traverse speed seems 
rather slow for the considerable heat input deriving from the rotating FSW tool to dissipate quickly enough, thus producing a low natural cooling rate. Therefore, it is possible that their resultant microstructure is affected by an applied forced cooling method, which is not disclosed, and the steel's different chemical composition to DH36.

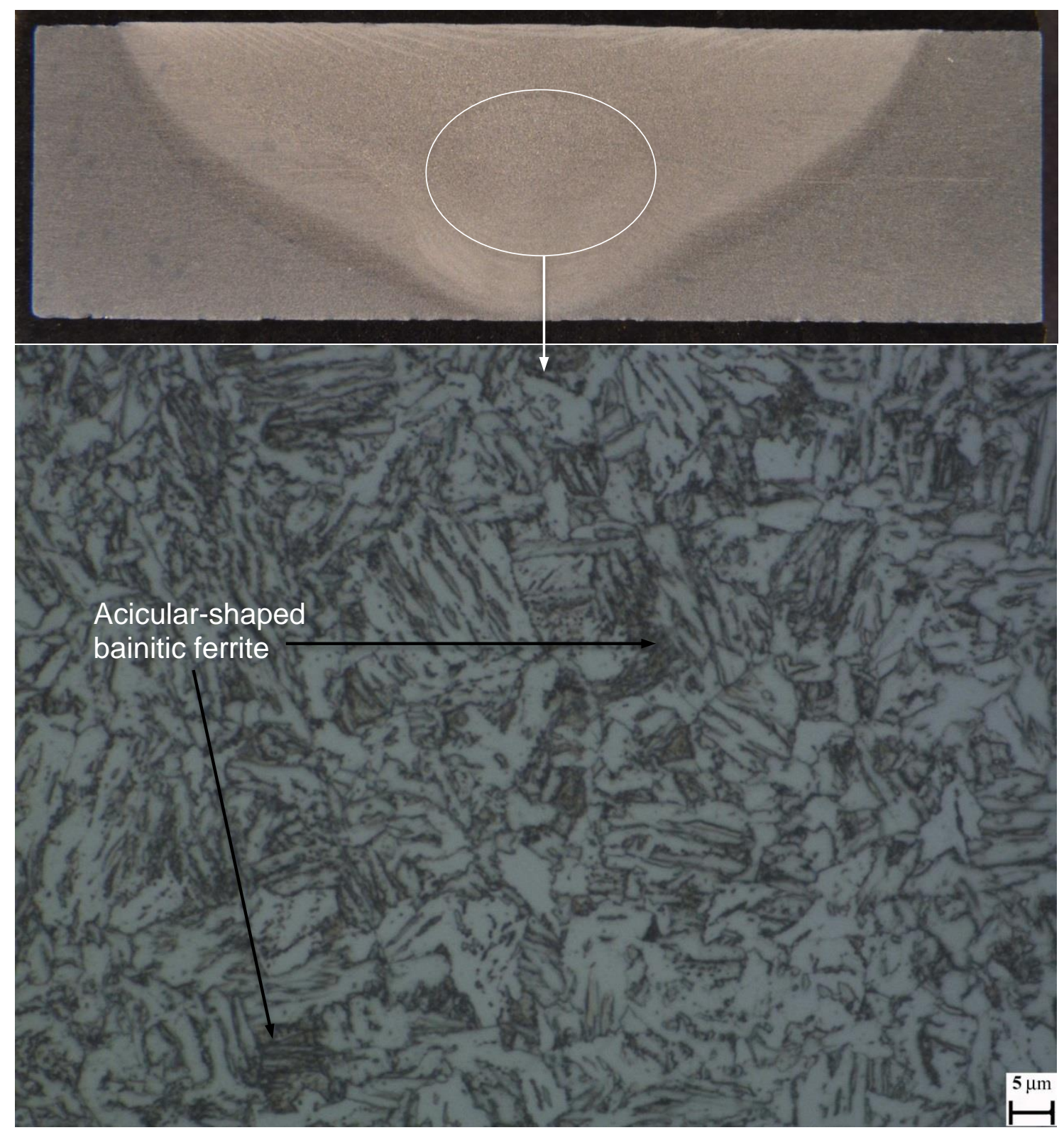

Fig. 10. W019C, microstructure of mid-TMAZ [x1000, Etched].

W021 has been classified in the group of slow weld parameters; contrary to other welds of this group however, it exhibits an acicular ferrite predominant microstructure. There is a suggestion that coarse carbides and small, more randomly mixed bainite-rich regions are observed. On the latter regions, prior austenite grain boundaries are believed to be present. In all, this group of welds is expected to have acceptable mechanical properties. As discussed earlier, another study [4] reports mainly acicular ferrite microstructure in the TMAZ of 
DH36 welds; thus, it can be concluded that the welding conditions have produced a comparable cooling rate to the one occurring in weld W021.

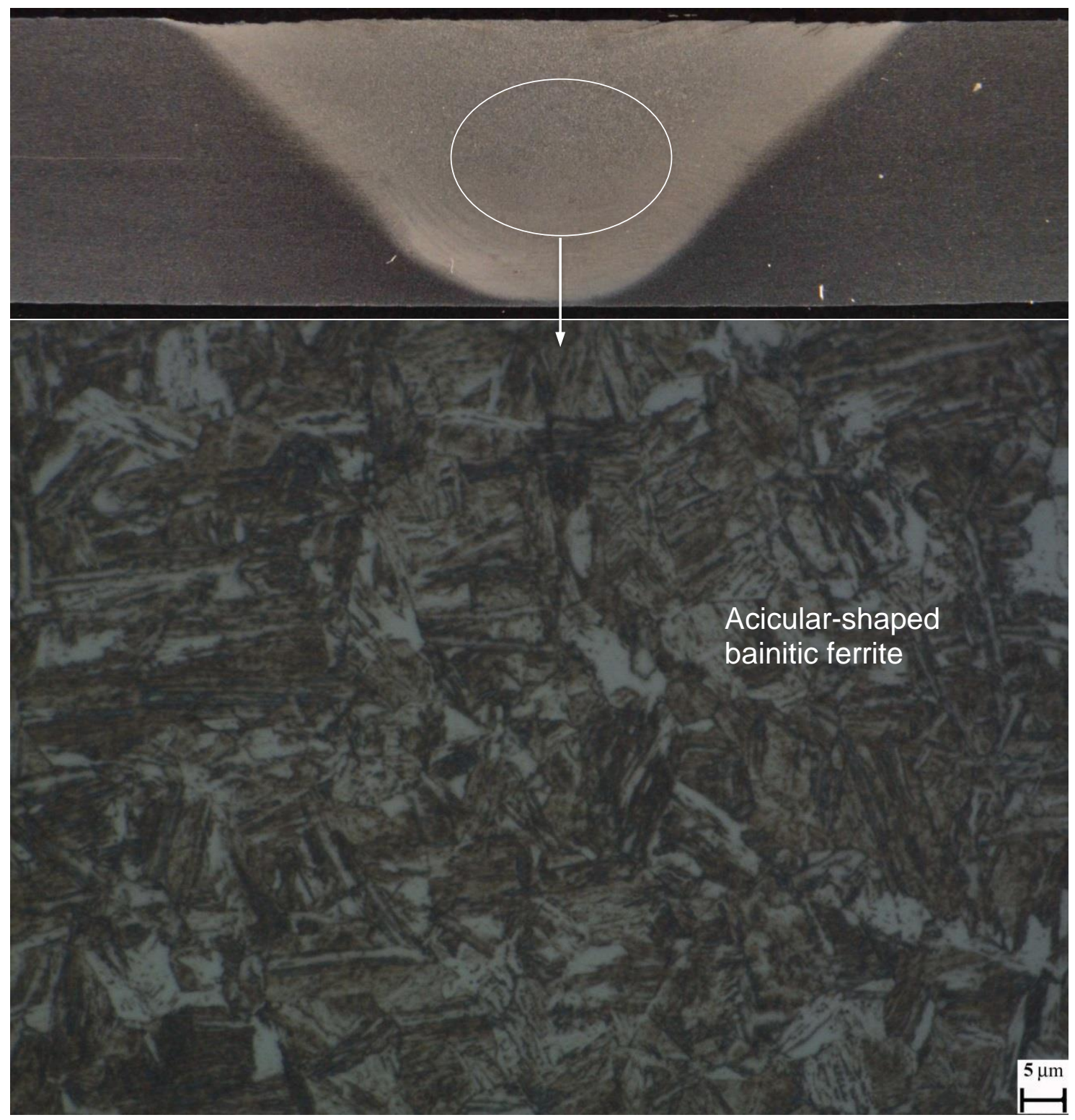

Fig. 11. W028, microstructure of mid-TMAZ [x1000, Etched].

In the intermediate group of welds with rotational speed of $400 \mathrm{rpm}$ and as traverse speed is seen to increase, the microstructure becomes more heterogeneous, with regions of increasing bainite content (suggesting an increased cooling rate). However, this heterogeneous microstructure does not seem to have a significant effect on the mechanical properties (see later). Still, weld W028 is very homogeneous, with an apparently acicular-shaped bainitic ferrite microstructure (Figure 11); this would suggest that a good balance of rotational and traverse speed has been achieved. In addition, prior austenite grain boundaries can be observed on the light optical microscope, only on the bainite predominant regions. 
The friction stir welding process appears to be tolerant to welding speed variations at the $450 \mathrm{rpm}$ rotational speed. Both welds in this intermediate group exhibit a homogeneous, fully acicular bainitic ferrite microstructure with prior austenite grain boundaries. Due to a marginally lower heat input, W029 presents a rather small heat affected zone; weld W030 however seems to be the product of an excellent intermediate set of parameters (Figure 12).

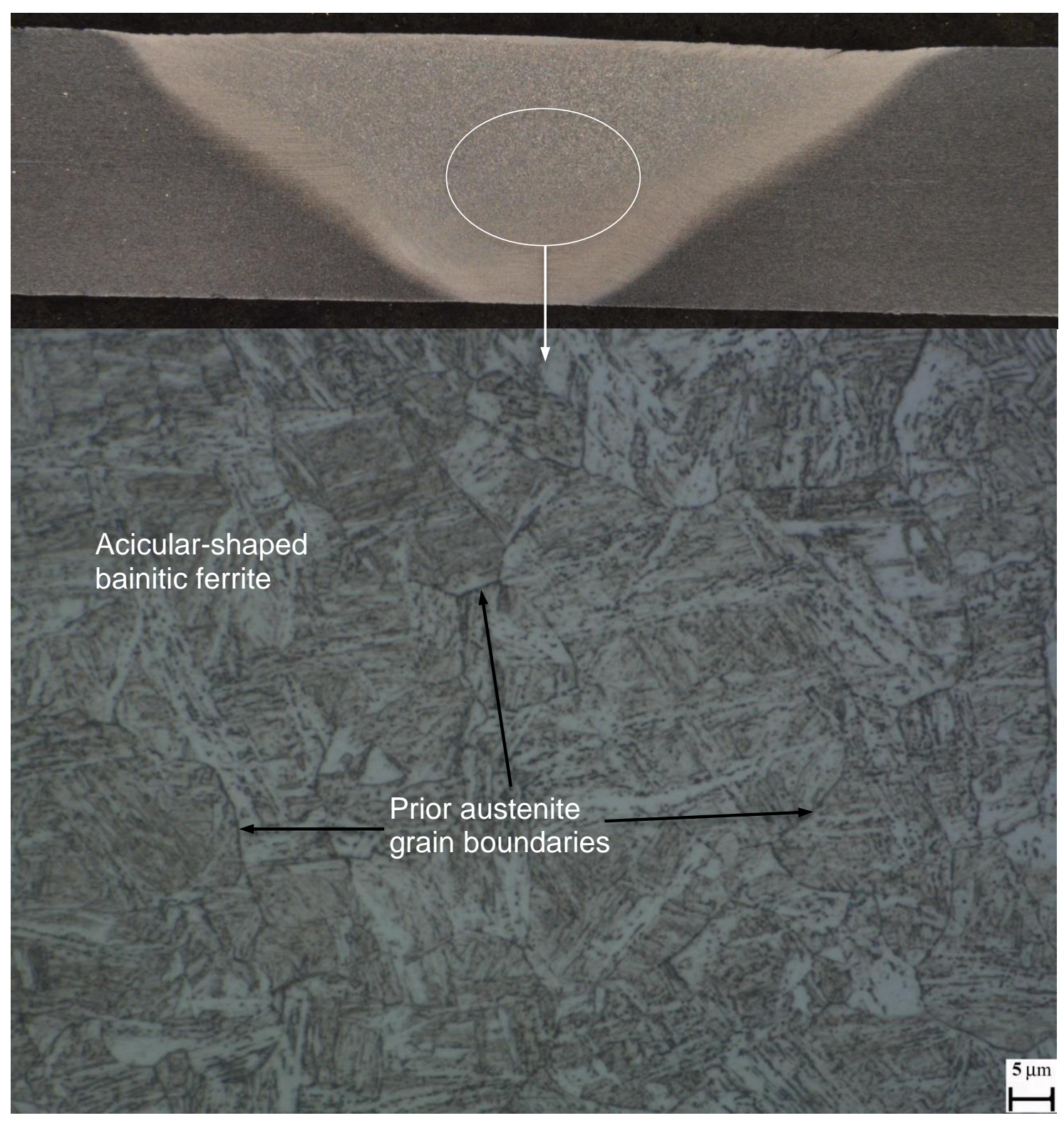

Fig. 12. W030, microstructure of mid-TMAZ [x1000, Etched].

At the high welding speed of $500 \mathrm{~mm} / \mathrm{min}$, the microstructure of all five welds becomes very heterogeneous, with poorly mixed regions of acicular ferrite and varying bainite content. The presence of bainite has increased considerably in this group due to the even higher cooling rate that it is expected to occur. Prior austenite grain boundaries are easily detected on the regions of bainite predominant microstructure. Two distinct microstructures co-exist within the TMAZ of weld W035 (Figure 13); these would be expected to act as stress concentration regions. Yet, this weld's parameters seem to have achieved a 
good balance of traverse and rotational speed that is translated into satisfactory tensile behaviour (see later). This could be attributed to the grain refinement and a suitable ratio of microstructures overtaking the negative effects of heterogeneity.

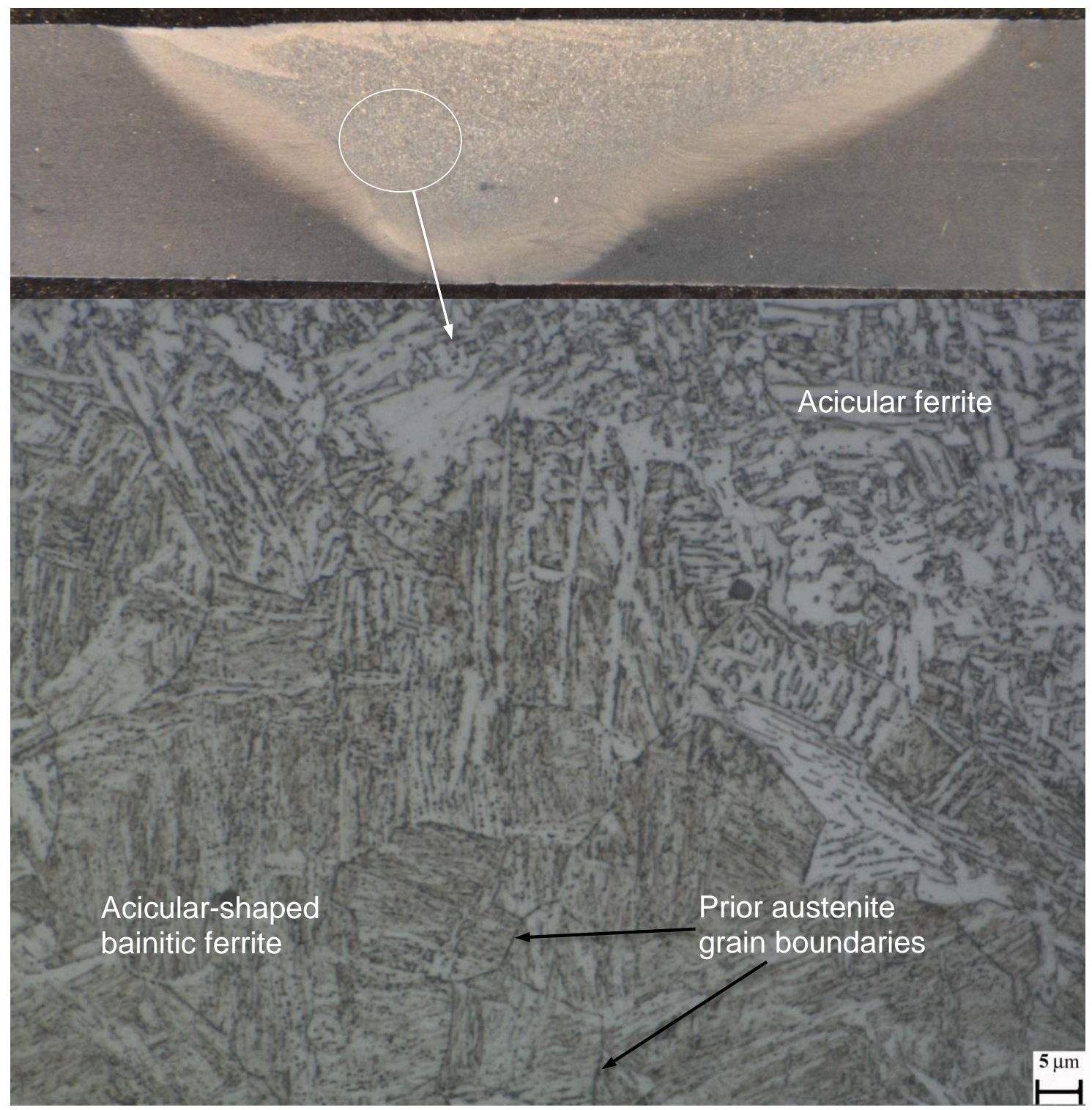

Fig. 13. W035, microstructure of mid-TMAZ AD side [x1000, Etched].

Reynolds et al. [3] report that a bainitic and martensitic (therefore acicular by definition) microstructure has evolved in the TMAZ using the same grade of steel and a marginally lower traverse speed of $450 \mathrm{~mm} / \mathrm{min}$. They [3] conclude that it is a consequence of the phase transformation of austenite during fast cooling, and as no ferrite is observed in this region, evidence of FSW elevating the steel's temperature above $A_{3}$. The rotational speed of this weld is not made clear in order to allow comparisons with the current welds. Still, the formation of martensite suggests that the cooling rate developed during their welding process is higher than the rate occurring herein. 
The process becomes very sensitive to parameters change, i.e. variations in rotational speed in this group of welds. Evidence for this can be drawn from the following two observations:

- Welds W035 and W036 only differ by 25 rpm in rotational speed; W036 however is rather unstable, as if steady state conditions have not been achieved (also see later) and with appreciable carbide precipitation.

- In two of the five welds in this group (W032 and W033), incomplete fusion appears on the advancing side, within which interconnected nonmetallic inclusions are detected. These flaws have a significant length with secondary paths, and are clearly expected to affect the mechanical properties of the weld.

There is evidence of minor weld root flaws for most of the examined welds; regions of insufficient or no welding of the original interface between the two plates. Moreover, some samples present a poor quality top surface with fissures introducing non-metallic inclusions in the TMAZ. Nevertheless, both types of flaws are regarded as processing features and have been reported to TWI for further investigation.

As a general note, no surface voids or cracks or others flaws are detected (except those mentioned above for welds W032 and W033) in the bulk of the weld zone (TMAZ), and especially in the top advancing side where the shear forces on the metal are expected to be the highest. Hence, high speed friction stir welding of steel grade $\mathrm{DH} 36$ is feasible; the process is tolerant to parameter variation in low and intermediate speeds but less tolerant at the highest speed (500 mm/min).

\subsection{Mechanical property assessment}

Stress vs. strain charts were plotted for each transverse tensile test to evaluate the consistency of the generated data and to determine the yield strength and ultimate tensile strength (UTS) of each sample. The calculated mechanical properties are outlined in Table 3.

The samples of fifteen out of the nineteen welds fractured in the parent material rather than the weld (all three samples per weld). This suggests that these fifteen sets of weld parameters produced welds of higher strength than the parent material. All samples prepared from the fourteen slow and intermediate welds (as classified in Table 1) fractured in the parent material. Even welds which consist of high acicular bainitic ferrite phase ratio and therefore could be expected to show brittle behaviour proved to be stronger than the parent material. Identical tensile behaviour is reported in other studies [3,4], where all transverse tensile samples produced from welds of similar sets of parameters fractured in the parent material, well away from the HAZ. Equally, welds with a very heterogeneous microstructure (e.g. W031), i.e. containing stress 
concentration regions which may act as crack initiation points, or welds with minor flaws such as weld root flaw or fissures on the top surface fractured in the parent material.

Table 3

Summary of DH36 FSW transverse tensile tests results.

\begin{tabular}{|c|c|c|c|c|c|c|}
\hline \multicolumn{3}{|c|}{ Weld } & \multicolumn{4}{|c|}{ Transverse tensile testing at Room Temperature } \\
\hline $\begin{array}{l}\text { Reference } \\
\text { number }\end{array}$ & $\begin{array}{c}\text { Rotational } \\
\text { Speed (rpm) }\end{array}$ & $\begin{array}{l}\text { Traverse Speed } \\
\quad(\mathrm{mm} / \mathrm{min})\end{array}$ & $\begin{array}{c}\text { Yield } \\
\text { Strength } \\
(0.2 \%), \mathrm{MPa}\end{array}$ & $\begin{array}{l}\text { UTS, } \\
\text { MPa }\end{array}$ & $\begin{array}{l}\text { Region of } \\
\text { fracture }\end{array}$ & $\begin{array}{l}\text { Fracture } \\
\text { mode }\end{array}$ \\
\hline & & & 395 & 530 & & \\
\hline \multirow[t]{3}{*}{ W019A } & 200 & 100 & 408 & 540 & PM & Ductile \\
\hline & & & 398 & 536 & & \\
\hline & & & 390 & 530 & & \\
\hline \multirow[t]{3}{*}{ W019B } & 200 & 110 & 394 & 536 & PM & Ductile \\
\hline & & & 386 & 535 & & \\
\hline & & & 401 & 536 & & \\
\hline \multirow[t]{3}{*}{ W019C } & 200 & 120 & 396 & 529 & PM & Ductile \\
\hline & & & 392 & 527 & & \\
\hline & & & 406 & 535 & & \\
\hline \multirow[t]{3}{*}{ W020A } & 200 & 130 & 407 & 536 & PM & Ductile \\
\hline & & & 401 & 533 & & \\
\hline & & & 398 & 521 & & \\
\hline \multirow[t]{3}{*}{ W020B } & 200 & 143 & 400 & 527 & PM & Ductile \\
\hline & & & 409 & 529 & & \\
\hline & & & 405 & 531 & & \\
\hline \multirow[t]{3}{*}{ W020C } & 200 & 156 & 396 & 523 & PM & Ductile \\
\hline & & & 397 & 525 & & \\
\hline & & & 320 & 512 & & \\
\hline \multirow[t]{3}{*}{ W021 } & 400 & 200 & 380 & 516 & PM & Ductile \\
\hline & & & 391 & 528 & & \\
\hline & & & 384 & 525 & & \\
\hline \multirow[t]{3}{*}{ W022 } & 400 & 250 & 384 & 523 & PM & Ductile \\
\hline & & & 381 & 519 & & \\
\hline & & & 383 & 522 & & \\
\hline \multirow[t]{3}{*}{ W023 } & 400 & 275 & 384 & 521 & PM & Ductile \\
\hline & & & 378 & 525 & & \\
\hline & & & 387 & 526 & & \\
\hline \multirow[t]{3}{*}{ W027 } & 400 & 325 & 387 & 525 & PM & Ductile \\
\hline & & & 388 & 524 & & \\
\hline & & & 390 & 528 & & \\
\hline \multirow[t]{3}{*}{ W028 } & 400 & 375 & 390 & 530 & PM & Ductile \\
\hline & & & 392 & 525 & & \\
\hline & & & 397 & 540 & & \\
\hline \multirow[t]{3}{*}{ W029 } & 450 & 400 & 396 & 534 & PM & Ductile \\
\hline & & & 393 & 532 & & \\
\hline & & & 399 & 539 & & \\
\hline \multirow[t]{3}{*}{ W030 } & 450 & 350 & 405 & 544 & PM & Ductile \\
\hline & & & 396 & 534 & & \\
\hline & & & 382 & 519 & & \\
\hline \multirow[t]{3}{*}{ W031 } & 300 & 250 & 385 & 514 & PM & Ductile \\
\hline & & & 386 & 522 & & \\
\hline & & & 383 & 457 & & \\
\hline \multirow[t]{2}{*}{ W032 } & 600 & 500 & 384 & 458 & Weld, AD & Brittle \\
\hline & & & 400 & 488 & & \\
\hline \multirow{2}{*}{ W033 } & & 500 & 412 & 526 & Weld, AD & Brittle \\
\hline & 650 & 500 & 408 & 563 & side & Brittle \\
\hline
\end{tabular}




\begin{tabular}{|c|c|c|c|c|c|c|}
\hline & & & 417 & 534 & & \\
\hline & & & 423 & 433 & & \\
\hline \multirow[t]{3}{*}{ W034 } & 575 & 500 & 429 & 462 & Weld, AD & Brittle \\
\hline & & & 442 & 480 & & \\
\hline & & & 382 & 519 & & \\
\hline \multirow[t]{3}{*}{ W035 } & 700 & 500 & 388 & 523 & PM & Ductile \\
\hline & & & 401 & 546 & & \\
\hline & & & 397 & 514 & Weld, AD & Brittle \\
\hline \multirow[t]{2}{*}{ W036 } & 675 & 500 & 390 & 458 & side & Brittle \\
\hline & & & 394 & 532 & PM & Ductile \\
\hline PM - 1 & \multirow{3}{*}{\multicolumn{2}{|c|}{ Longitudinal direction }} & 339 & 521 & & \\
\hline PM - 2 & & & 340 & 525 & PM & Ductile \\
\hline PM - 3 & & & 340 & 526 & & \\
\hline
\end{tabular}

The group of fast welds $(500 \mathrm{~mm} / \mathrm{min})$ demonstrated a different behaviour. All samples from welds W032, W033 and W034 fractured in the weld, and specifically in a brittle-like manner on the outer boundary of the advancing side. This fracture region appears to correspond to the top AD TMAZ region where non-metallic inclusions were found to be interconnected in an incomplete fusion characteristic. This feature was observed in welds W032 and W033.

Two samples from weld W036 fractured inside the weld (brittle fracture on outer $A D$ side) and one fractured in the parent material in a ductile manner (Figure 14). In fact, there is a noteworthy difference in the fracture faces of the first two samples; one sample's fracture face has the FSW tool's features imprinted on it (on the mid-AD TMAZ, Figure 14a). This denotes that the metal was mechanically worked (similar to forging) by the FSW tool in this region rather than thermo-mechanically stirred, perhaps due to lower heat input. The second sample presents markings consistent with lower (than required) temperature material flow patterns, suggesting lower heat input in this region (Figure 14b). Figure 14c presents the third sample examined from weld W036, with a typical ductile fracture. Such observations indicate that this set of parameters is on a threshold value producing welds where steady state conditions have not been reached (an "unstable" weld).

W035 is the only one of the fast weld category that fractured in the parent material with a typically ductile fracture. Although a very heterogeneous microstructure (with possible stress concentration regions associated with this heterogeneity) has been observed on the optical microscope, all three samples proved to be stronger than the parent material. It would appear that this set of parameters achieves a good balance of rotational speed (sufficient heat input for proper thermo-mechanical stirring) and traverse speed (affecting the cooling rate which governs the ratio of phases) to produce acceptable quality welds. 

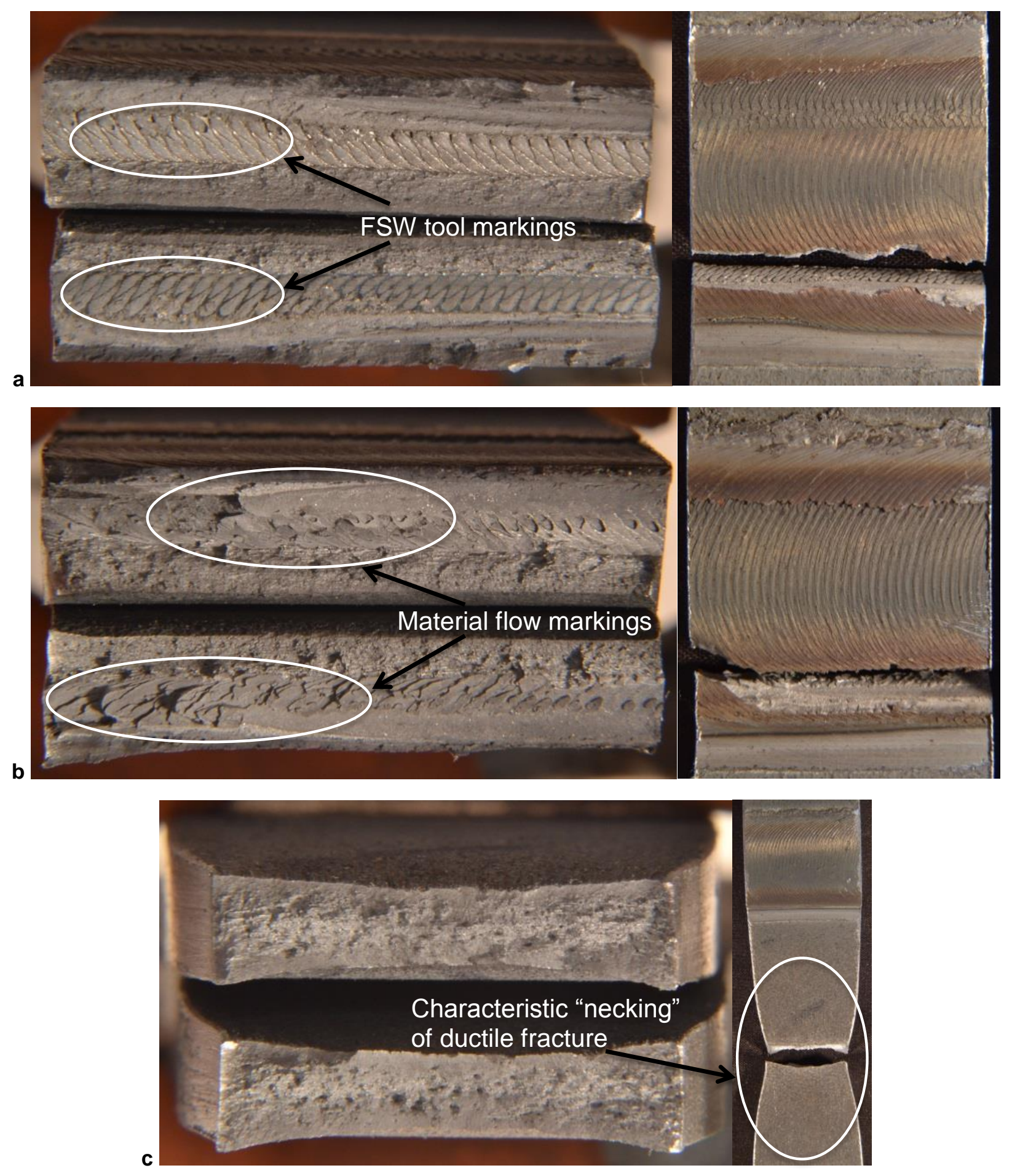

Fig. 14. Three samples of W036 exhibiting different fracture behaviour.

On the hardness of the weld region and for reporting purposes, two welds from each group of slow, intermediate and fast welds will be discussed herein. In addition, all hardness values presented in Figure 15 refer to the top-TMAZ of each weld sample, i.e. $1 \mathrm{~mm}$ below the top surface (Figure 6). In the slow and intermediate welds (Figures 15a \& 15b), the hardness of the weld is higher than that of the parent material but not at levels which can cause concern considering their tensile test results. The hardness of each weld seems to be symmetrical across the weld region, with a relatively even distribution from 
advancing to retreating side of the TMAZ. Further, the hardness of the weld region in both groups is seen to increase with increasing cooling rate of the weld. In absolute terms, both intermediate welds have produced higher hardness values compared to the group of slow welds, as a result of their lower heat input and higher cooling rate hence increasing bainite content.
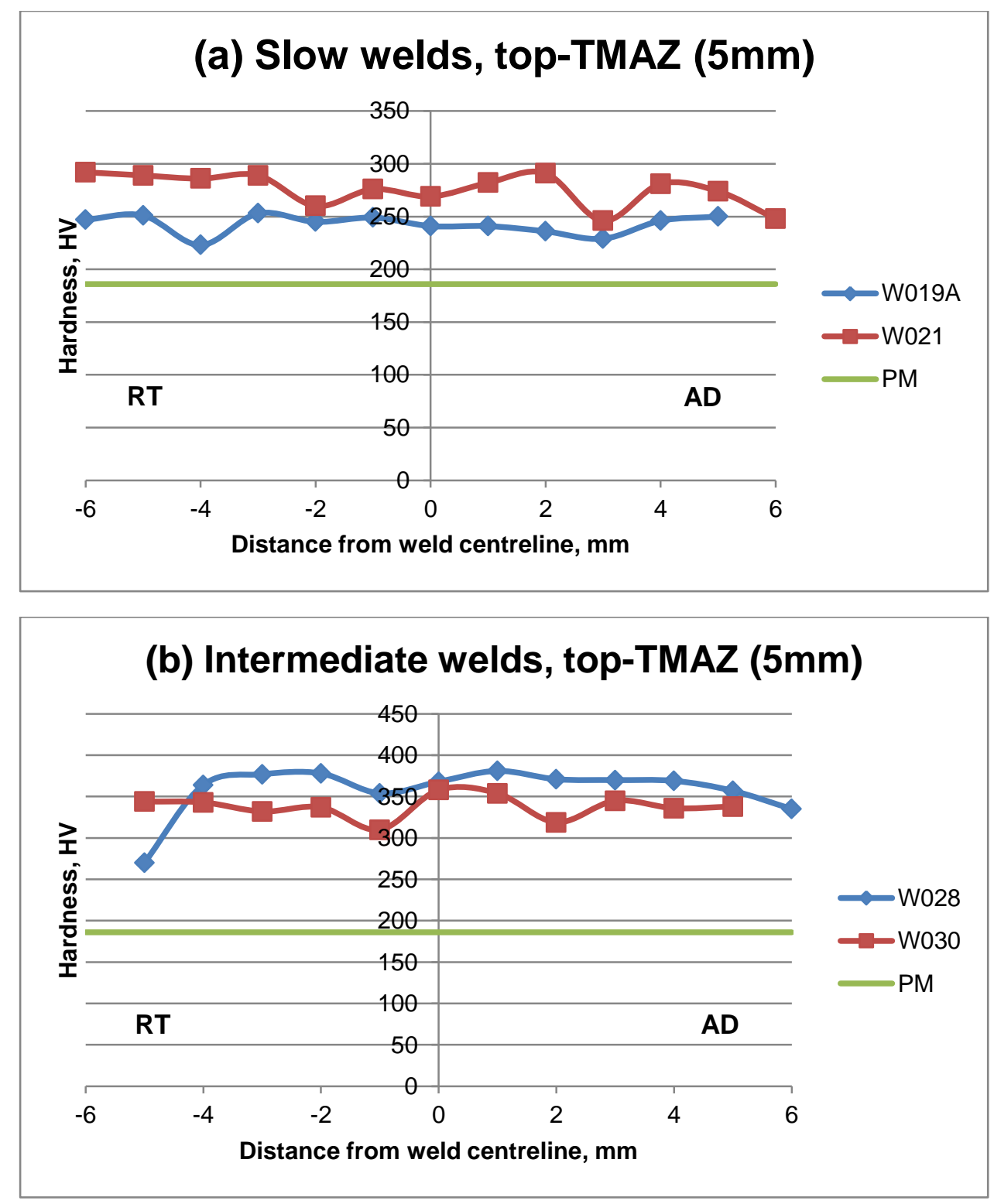


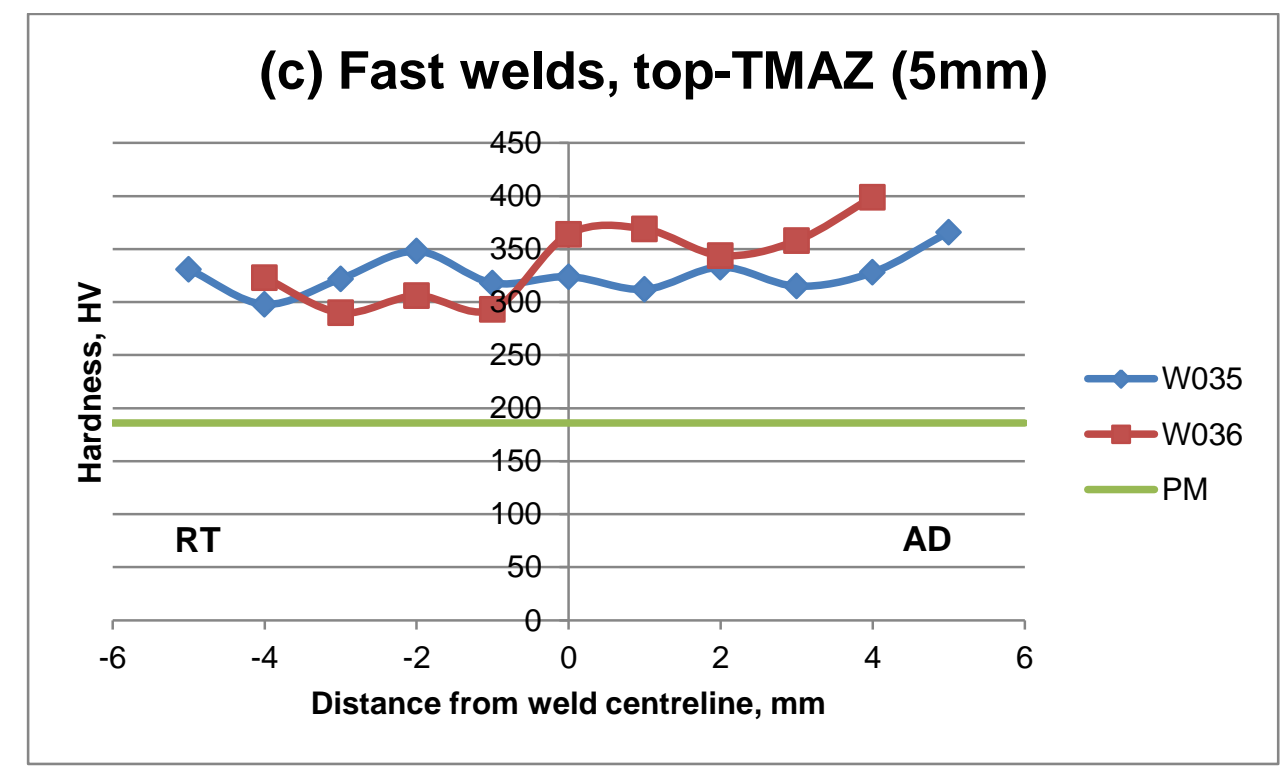

Fig. 15. Micro-hardness distribution of the weld region for three groups of weld parameters.

In the group of fast welds (Figure 15c), W035 exhibits a high but still reasonable range of hardness values with minor variations across the weld region. This may partly explain the excellent behaviour of this specific weld's samples in the transverse tensile tests. As expected due to its higher cooling rate, W036 is seen to produce higher hardness values particularly on the advancing side, and with more pronounced variations. This reflects the microstructural heterogeneity of this weld with region of varying bainite concentration, thus seems to suggest that different regions of the welded material, as it is stirred from the advancing to the retreating side, are experiencing different cooling rates. The very high hardness value on the outer advancing side should correlate with the same weld's tensile samples fracturing at the same position. In absolute terms again, the fast welds have produced similar hardness levels to the intermediate group suggesting similar cooling rates.

Such variations in the hardness distribution within the TMAZ of most welds currently examined are often reported by other researchers. Ghosh et al. [5] note that the significant variations of hardness within the weld zone of all welding parameters examined occur due to the heterogeneity of the resultant microstructure, from weld nugget to heat affected zone. Further, the differences in peak hardness between weld nugget regions depend on the weld parameters used hence the subsequent cooling rate of each weld. Cho et al. [6] argue that the substantially higher hardness found in the stir zone (central TMAZ) is caused by the acicular shaped bainitic ferrite microstructure. Similar microstructure is observed in most of the intermediate and high speed welds of this study but with smaller variations in the hardness of the TMAZ, suggesting a reasonably homogeneous microstructural distribution. 


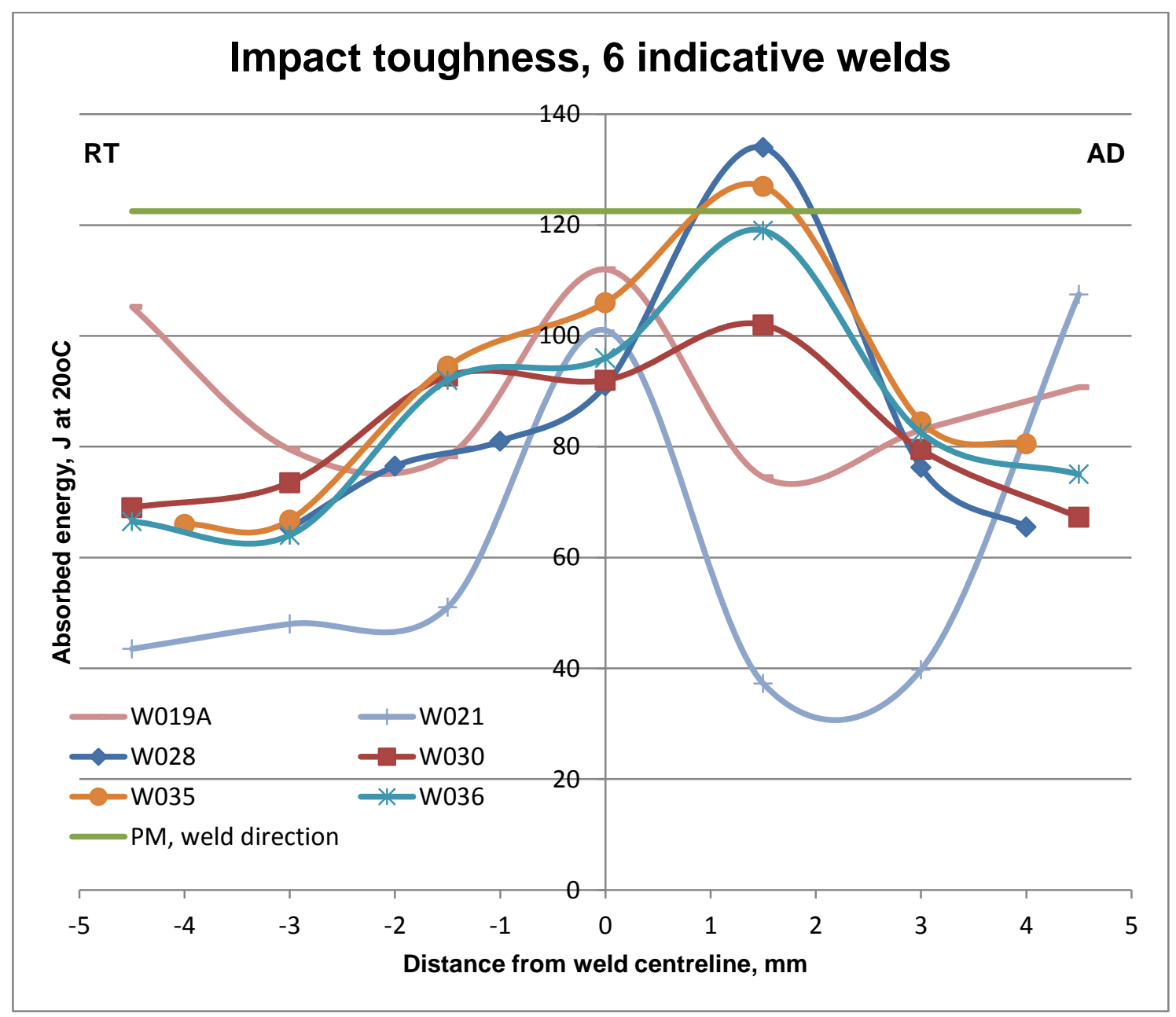

Fig. 16. Impact toughness distribution in the weld region for six sets of weld parameters at $20^{\circ} \mathrm{C}$.

The impact toughness data presented in Figure 16 have been normalised to a $10 \times 10 \mathrm{~mm}$ equivalent by a scaling factor of $3 / 2$, as discussed by McPherson et al. [4]. The impact toughness of most welds at $20^{\circ} \mathrm{C}$ appears to have been reduced compared to the parent material (Figure 16). The slow welds follow a similar pattern of peak values on the weld centreline and lowest values nearing both sides of the TMAZ. It appears that the presence of acicular ferrite in W021 has a detrimental effect on the impact toughness when compared to the ferriterich (with refined grains of random geometry) microstructure in W019A. All intermediate and fast welds exhibit a similar trend in impact toughness distribution, with a peak observed in the inner TMAZ of the advancing side and gradual decrease towards the outer boundaries of the TMAZ on both sides. The homogeneous acicular bainitic ferrite microstructure observed in W028 has produced marginally higher impact toughness in the AD TMAZ than the heterogeneous microstructure of W035. The latter is characterised as having two distinct structures, acicular bainitic ferrite and acicular ferrite; as with weld W021 discussed above, the presence of acicular ferrite seems to be responsible for the slightly reduced impact toughness of W035. Considerable variation between the impact toughness of the advancing and retreating sides is apparent in the intermediate and fast welds. It should be highlighted that two 
sets of parameters which were previously identified as being well balanced, W028 and W035, overmatch the parent plate's impact toughness in the inner AD TMAZ.

The data in Figure 16 reveal that increasing the traverse speed from 100 $\mathrm{mm} / \mathrm{min}$ to $375 \mathrm{~mm} / \mathrm{min}$ and $500 \mathrm{~mm} / \mathrm{min}$ delivers a significant effect of improving the impact toughness on the advancing side, although having a lesser improvement on the retreating side. The impact toughness in both sides of the outer TMAZ however is seen to decrease to some extent with the intermediate and fast traverse speed. Still, the improvement in impact toughness offers a level of confidence in increasing the FSW traverse speed.

\section{Conclusions}

1. A comprehensive study, consisting of 19 friction stir welds of $2000 \times 200 \times 6$ $\mathrm{mm}$ DH36 steel plates has generated an extensive data set to account for a wide range of typical and atypical process parameters. This has resulted in the development of a preliminary FSW parameter envelope based on the outcomes of microstructural evaluation and mechanical testing.

2. The welding (traverse) speed on DH36 steel has been increased to a great extent compared to the conventionally used speed of $100 \mathrm{~mm} / \mathrm{min}$. This represents considerable potential economic advantages in terms of the competitiveness of FSW to conventional welding processes.

3. An initial understanding of the relationship between weld parameters and the effect of these on weld microstructures and mechanical properties has been established. From this, it is evident that FSW generates a very complex metallurgical system in which the slow speeds result in a very refined, ferrite rich microstructure, the intermediate speeds produce predominantly acicular bainitic ferrites, and the fast speeds result in a heterogeneous microstructure with distinct regions of acicular ferrite and acicular bainitic ferrite.

4. A number of weld parameters have been identified which may produce fast (in the region of $400 \mathrm{~mm} / \mathrm{min}$ ) or very fast (potentially up to $500 \mathrm{~mm} / \mathrm{min}$ ) welds of acceptable quality that are highly competitive to conventional fusion welding techniques.

5. Increasing welding (traverse) speed is seen to improve the impact toughness of the weld without compromising strength and hardness.

Subsequent work will include a further refinement of the high speed weld parameters identified in this characterisation study and a comprehensive fatigue testing program. 


\section{Acknowledgements}

The authors gratefully acknowledge the financial support of the European Union which has funded this work as part of the Collaborative Research Project HILDA (High Integrity Low Distortion Assembly) through the Seventh Framework Programme (SCP2-GA-2012-314534-HILDA).

\section{References}

[1] W.M. Thomas, E.D. Nicholas, J.C. Needham, M.G. Murch, P. TempleSmith, and C.J. Dawes: GB Patent No. 9125978.8, International Patent No. PCT/GB92/02203.

[2] W.M. Thomas, P.L. Threadgill, and E.D. Nicholas: Sci. Technol. Weld. Join., 1999, vol. 4 (6), pp. 365-72.

[3] A.P. Reynolds, W. Tang, M. Posada, and J. Deloach: Sci. Technol. Weld. Join., 2003, vol. 8 (6), pp. 455-60.

[4] N.A. McPherson, A.M. Galloway, S.R. Cater, and S.J. Hambling: Sci. Technol. Weld. Join., 2013, vol. 18 (5), pp. 441-50.

[5] M. Ghosh, K. Kumar, and R.S. Mishra: Metall. Mater. Trans. A, 2012, vol. 43A, pp. 1966-75.

[6] H.H. Cho, S.H. Kang, S.H. Kim, K.H. Oh, H.J. Kim, W.S. Chang, and H.N. Han: Mater. Des., 2012, vol. 34, pp. 258-67.

[7] S. Kumar, S. Kumar, and A. Kumar: Proc. Inst. Mech. Eng., Part C, 2012, vol. 227 (6), pp. 1150-63.

[8] M. Ghosh, K. Kumar, S.V. Kailas, and A.K. Ray: Mater. Des., 2010, vol. 31, pp. 3033-37.

[9] Z.Y. Ma: Metall. Mater. Trans. A, 2008, vol. 39 (3), pp. 642-58.

[10]H. Liu, M. Maeda, H. Fuji, and K. Nogi: J. Mater. Sci. Lett., 2003, vol. 22 (1), pp. 41-3.

[11]British Standards Institution: BS EN ISO 6892-1:2009, London, U.K., August 2009.

[12]British Standards Institution: BS EN ISO 148-1:2010, London, U.K., November 2010. 